\title{
Association of Serum Sclerostin Level, Coronary Artery Calcification, and Patient Outcomes in Maintenance Dialysis Patients
}

\author{
Yifei Ge Buyun Wu Xiangbao Yu Ningning Wang Xueqiang Xu \\ Ming Zeng Bo Zhang Huijuan Mao Changying Xing \\ Department of Nephrology, The First Affiliated Hospital of Nanjing Medical University, Nanjing, China
}

\author{
Keywords \\ Sclerostin · Coronary artery calcification · Maintenance \\ dialysis - Patient outcomes
}

\begin{abstract}
Objective: The objective of this study is to investigate the association between the serum sclerostin, the coronary artery calcification (CAC), and patient outcomes in maintenance dialysis patients. Methods: We performed a prospective cohort study of 65 maintenance dialysis patients in 2014, including 39 patients on peritoneal dialysis and 26 on hemodialysis, and followed up for 5 years. Parameters of mineral metabolism including bone-specific alkaline phosphatase, fibroblast growth factor 23, sclerostin, and other biochemical factors were determined at the baseline. Meanwhile, the CAC score was analyzed by cardiac computed tomography. Results: Serum sclerostin in hemodialysis patients was significantly higher than that in peritoneal dialysis patients $(632.35 \pm 369.18$ vs. $228.85 \pm 188.92, p<0.001)$. The patients with $C A C$ were older, receiving hemodialysis, lower $\mathrm{Kt} / \mathrm{V}$, and had longer dialysis vintage, as well as higher levels of serum 25-(OH)-vit $\mathrm{D}$ and sclerostin. In multivariate logistic regression analysis, older age and lower $\mathrm{Kt} / \mathrm{V}$ were risk factors for CAC. The area under the receiver operating characteristic curves for prediction of CAC by sclerostin was 0.74 ( $95 \%$ confidence interval $0.605-0.878, p=0.03$ ), and the cutoff value of sclerostin is $217.55 \mathrm{pg} / \mathrm{mL}$ with the sensitivity 0.829 and specificity 0.619 . After 5 years of follow-up, 51 patients sur-
\end{abstract}

karger@karger.com www.karger.com/bpu

Karger $\stackrel{\text { ' }}{5}$

GOPEN ACCESS
(C) 2021 The Author(s)

Published by S. Karger AG, Basel

This is an Open Access article licensed under the Creative Commons Attribution-NonCommercial-4.0 International License (CC BY-NC) (http://www.karger.com/Services/OpenAccessLicense), applicable to the online version of the article only. Usage and distribution for commercial purposes requires written permission. vived. The patients in the survival group had significantly lower age, sclerostin levels, and low CAC scores than the nonsurvival group. Old age ( $\geq 60$ years, $p<0.001)$ and high CAC score ( $\geq 50$ Agatston unit, $p=0.031$ ) were significant risk factors for the patient survival. Conclusions: Sclerostin is significantly elevated in dialysis patients with CAC. But sclerostin is not a risk factor for CAC. After 5 years of follow-up, patients in the survival group are younger and have lower sclerostin levels and CAC scores. But sclerostin levels are not independent risk factors for high mortality in dialysis patients.

(C) 2021 The Author(s)

Published by S. Karger AG, Basel

\section{Introduction}

Chronic kidney disease-mineral bone disorder (CKDMBD) is a major syndrome that occurs secondary to declining renal function and usually predicts poor outcomes $[1,2]$. However, the exact mechanism of the relationship between the CKD-MBD and a high mortality is not yet fully elucidated. Meanwhile, the abnormal bone metabolism plays an important role in the pathogenesis of CKDMBD $[3,4]$. The various bone metabolic factors may be associated with the CKD-MBD, such as calcium, phosphate, parathyroid hormone (PTH), and vitamin D [5]. Recent studies have identified the new molecules including fibroblast growth factor 23 (FGF23), bone-specific alkaline phosphatase (BALP), and sclerostin may be in- 


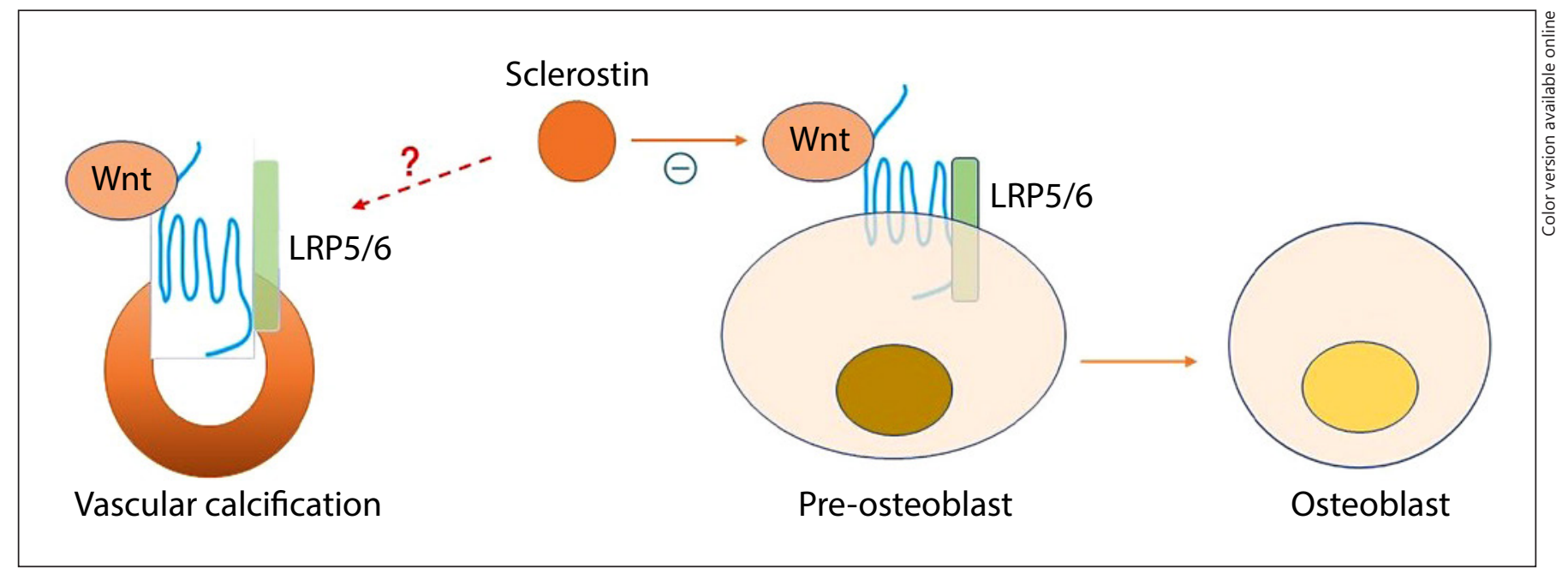

Fig. 1. Sclerostin: regulation, bone effect, and (hypothetical) link with vascular calcifications. Sclerostin inhibits the Wnt receptor (LRP5/6), inducing inhibition of differentiation and proliferation of the osteoblast precursors into mature osteoblasts. The link between sclerostin and vascular calcification is still uncertain. Wnt, Winglesstype integration site; LRP, lipoprotein receptor-related protein.

volved in the CKD-MBD and also become the risk makers for the cardiovascular outcomes $[6,7]$. As a key aspect in the CKD-MBD, vascular calcification is an independent risk factor for the cardiovascular disease and is related to the adverse cardiovascular events $[8,9]$. Among these emerging biomarkers, it is essential to find an indicator that could predict the presence and extent of vascular calcification. Sclerostin, an osteocyte-derived glycoprotein has attracted the researchers' attention $[10,11]$.

Sclerostin is the secreted product of the SOST gene in osteocytes. As a soluble inhibitor of Wingless-type mouse mammary tumor virus integration site (Wnt) signaling, sclerostin binds to the co-receptors low-density lipoprotein receptor-related protein- 5 or lipoprotein receptor-related protein -6 and blocks their association with Wnts [12]. The effect of canonical Wnt signaling on bone is mediated by simulation of stem cells and pre-osteoblast proliferation, induction of osteoblastogenesis, and attenuation of osteoclastogenesis $[12,13]$. Recently, the potential role of sclerostin in vascular calcification, in particular CKD patients, has been widely discussed in different studies [14-16]. However, the relationship between human serum sclerostin and vascular calcification is still unclear. The pathophysiological mechanism of sclerostin is shown in Figure 1. To date, some studies showed a positive correlation in vascular calcification [16-19]. On the other hand, a negative correlation was found between sclerostin and vascular calcification in 2 cross-sectional studies and a prospective observational cohort study $[11,20]$. Claes et al.
[21] reported that the positive univariate correlation between aortic calcifications and sclerostin levels became inverse in multivariate analysis in predialysis patients. The previous studies also included vastly different population samples, such as hemodialysis patients, ESRD patients (predialysis, hemodialysis, and peritoneal dialysis), patients in CKD stage 3-4, and patients in CKD stage 1-5 not receiving dialysis. In the current study, we measured serum sclerostin and other CKD-MBD biomarkers, inflammation biomarkers, biochemical parameters, and degree of coronary artery calcification (CAC) score by cardiac computed tomography $(\mathrm{CT})$ in ESRD patients receiving hemodialysis and peritoneal dialysis. Meanwhile, we also examined the relationship between these biomarkers and another cardiovascular outcomes-left ventricular mass index (LVMI) or patient survival after a 5 -year follow-up period.

\section{Materials and Methods}

Study Design

A total of 65 maintenance dialysis patients from the Department of Nephrology at the First Affiliated Hospital of Nanjing Medical University were enrolled in this prospective cohort study between November 2014 and April 2015. Among these patients, 26 were undergoing hemodialysis, 39 were undergoing peritoneal dialysis. Inclusion criteria were aged 18 years or older and were able to provide consent. The patients were excluded if they had any acute inflammation, malignancy, acute myocardial infarction, pulmonary edema, and heart failure at the time of blood sample collection. The patients were followed up for 5 years. The study was 
Table 1. Demographic and biochemical characteristics of maintenance dialysis patients

\begin{tabular}{|c|c|c|c|}
\hline & Total $(n=65)$ & $\mathrm{HD}(n=26)$ & $\mathrm{PD}(n=39)$ \\
\hline Male, $n(\%)$ & $34(52.3)$ & $19(73.1)$ & $15(38.5)$ \\
\hline Age, years & $48.38 \pm 13.18$ & $54.62 \pm 12.45$ & $44.23 \pm 12.09$ \\
\hline Weight, kg & $62.96 \pm 14.64$ & $66.2 \pm 14.41$ & $60.88 \pm 14.6$ \\
\hline $\mathrm{BMI}, \mathrm{kg} / \mathrm{m}^{2}$ & $22.86 \pm 4.24$ & $23.55 \pm 4.58$ & $22.42 \pm 4.01$ \\
\hline Hemoglobin, g/L & $106.11 \pm 16.78$ & $106.04 \pm 16.15$ & $106.15 \pm 17.40$ \\
\hline BALP, $\mu \mathrm{g} / \mathrm{L}$ & $20.56 \pm 10.11$ & $17.96 \pm 9.58$ & $22.42 \pm 4.01$ \\
\hline Calcium, mmol/L & $2.55 \pm 0.20$ & $2.41 \pm 0.18$ & $2.48 \pm 0.21$ \\
\hline Phosphorus, mmol/L & $1.68 \pm 0.60$ & $1.73 \pm 0.59$ & $1.65 \pm 0.60$ \\
\hline Serum ferritin, $\mathrm{ng} / \mathrm{mL}$ & $282.08 \pm 257.01$ & $200.73 \pm 242.86$ & $336.31 \pm 254.75$ \\
\hline $25(\mathrm{OH})$-vitamin $\mathrm{D}, \mathrm{ng} / \mathrm{mL}$ & $33.84 \pm 27.41$ & $59.42 \pm 25.72$ & $16.79 \pm 9.17$ \\
\hline Sclerostin, pg/mL & $297.00(156.85,607.58)$ & $632.35 \pm 369.18$ & $228.85 \pm 188.92$ \\
\hline hsCRP, mg/L & $1.37(0.54,4.01)$ & $1.47(0.48,4.00)$ & $1.19(0.54,4.05)$ \\
\hline CAC score, AU & $6.10(0.00,130.80)$ & $91.80(2.30,665.15)$ & $0.00(0.00,47.00)$ \\
\hline $\mathrm{FGF} 23, \mathrm{pg} / \mathrm{mL}$ & $15,844.21(2,875.01,52,277.40)$ & $24,907.51(6,901.98,53,736.12)$ & $13,194.21(1,916.72,52,831.90)$ \\
\hline Calcitriol use, $n(\%)$ & $39(60.0)$ & $23(88.5)$ & $16(41.0)$ \\
\hline Ca-based phosphate binders use, $n(\%)$ & $41(63.1)$ & $24(92.3)$ & $17(43.6)$ \\
\hline Ca-free phosphate binders use, $n(\%)$ & $3(4.6)$ & 0 & $3(7.7)$ \\
\hline Calcimimetic use, $n(\%)$ & 0 & 0 & 0 \\
\hline
\end{tabular}

BALP, bone-specific alkaline phosphatase; LVMI, left ventricular mass index; iPTH, intact parathyroid hormone; hsCRP, hypersensitive C reactive protein; CAC score, coronary artery calcification score; FGF23, fibroblast growth factor 23; BMI, body mass index; Au, Agatston unit.

approved by the Ethics Committee of the First Affiliated Hospital of Nanjing Medical University. Written informed consent was obtained from each of the subjects.

Data on gender, age, body mass index, dialysis duration, primary disease, hypertension, and whether or not combined with diabetes mellitus were collected. During the follow-up period, blood biochemistry, intact PTH, sclerostin, FGF23, etc., imaging examinations such as echocardiogram and coronary artery CT scan were tested once a year.

\section{Biochemical Measurement}

Blood samples were collected from the participants in the morning after an overnight fast. Parameters of serum albumin, calcium, phosphorus, and alkaline phosphatase were measured by standard autoanalyzer techniques (Beckman AU5800). The hemoglobin level was analyzed with an automated hematology analyzer (Sysmex XT 4000i, GMI Inc.). The intact PTH (iPTH) level was measured using a UniCel DxI800 Access Immunoassay System (Beckman Coulter, Inc., Fullerton, CA, USA). Serum 25(OH)-D was measured by an electrochemiluminescence immunoassay (Modular Analytics E170, Roche Diagnostis, Mannheim, Germany). Bone alkaline phosphatase was determined using a solid-phase, monoclonal antibody immunoenzymetric assay (Ostase BAP, Immunodiagnostic Systems, Tyne \& Wear, UK). Plasma FGF23 was measured using a human c-terminal ELISA kit (Immutopics, San Clemente, CA, USA). Serum sclerostin level was measured using ELISA (R\&D companies, America). LVMI was calculated according to the results of colored Doppler echocardiography.

\section{Cardiac CT and CAC Score}

Cardiac CT scans were performed using a 64-channel detector scanner (LightSpeed VCT; General Electric [GE] Healthcare, Milwaukee, WI, USA) in cine mode. Scans were ECG-gated, and a standard noncontrast protocol was used with a tube voltage of $100 \mathrm{kV}$, tube current of $200 \mathrm{~mA}, 350 \mathrm{~ms}$ rotation time, $2.5 \mathrm{~mm}$ slice thickness, and displayed field of $25 \mathrm{~cm}$. Calcium deposits in the coronary arteries were identified by a radiologist with Level 2 competence and over 9 years of experience in interpretation of cardiac CT (JR). The data were processed and analyzed using an Advantage Workstation 4.4 (GE Healthcare). Smartscore 4.0 (GE Healthcare) was used to assess $\mathrm{CAC}$ scores. Calcified plaques were considered to be present if values crossed the standard threshold of 130 Hounsfield units. CAC scores were expressed in Agatston units (AUs) as described previously in detail. Total CAC score was calculated as the sum of the CAC scores in the left main artery, the left anterior descending artery, the left circumflex artery, and the right coronary artery.

\section{Statistical Analysis}

Normally distributed variables are expressed in mean \pm standard error and non-normally distributed variables as median $\left(25^{\text {th }}\right.$ and $75^{\text {th }}$ percentiles), as appropriate. The correlation between the 2 variables was assessed by univariate regression. The comparison between 
Table 2. Clinical and biochemical parameters according to values below and above median sclerostin

\begin{tabular}{|c|c|c|c|}
\hline & $\begin{array}{l}\text { Below median } \\
(n=28)\end{array}$ & $\begin{array}{l}\text { Above median } \\
(n=28)\end{array}$ & $p$ value \\
\hline Male, $n(\%)$ & $12(42.9)$ & $20(71.4)$ & 0.031 \\
\hline Age, years & $41.25 \pm 10.88$ & $54.64 \pm 12.35$ & $<0.001$ \\
\hline Height, cm & $164.43 \pm 9.82$ & $167.11 \pm 7.67$ & 0.340 \\
\hline Weight, kg & $61.24 \pm 16.37$ & $65.94 \pm 12.57$ & 0.239 \\
\hline Albumin, $g / \mathrm{L}$ & $42.34 \pm 3.75$ & $38.96 \pm 3.09$ & 0.001 \\
\hline $\mathrm{BALP}, \mu \mathrm{g} / \mathrm{L}$ & $20.05(15.50,30.40)$ & $15.40(11.70,22.90)$ & 0.068 \\
\hline Calcium, $\mathrm{mmol} / \mathrm{L}$ & $2.48 \pm 0.18$ & $2.44 \pm 0.19$ & 0.385 \\
\hline Phosphorus, mmol/L & $1.64 \pm 0.50$ & $1.76 \pm 0.72$ & 0.472 \\
\hline Serum ferritin, $\mathrm{ng} / \mathrm{mL}$ & $222.50(71.20,405.10)$ & $231.00(89.70,355.18)$ & 0.961 \\
\hline $25(\mathrm{OH})$-vitamin $\mathrm{D}, \mathrm{ng} / \mathrm{mL}$ & $16.37(10.21,37.43)$ & $44.32 \pm 27.37$ & 0.015 \\
\hline $\mathrm{iPTH}, \mathrm{pg} / \mathrm{mL}$ & $310.00(107.60,691.80)$ & $173.50(36.40,357.85)$ & 0.023 \\
\hline hsCRP, mg/L & $1.63(0.37,5.24)$ & $1.98(0.69,4.22)$ & 0.372 \\
\hline CAC score, Agatston unit & $0(0,18.20)$ & $81.65(3.07,636.35)$ & 0.002 \\
\hline FGF23, pg/mL & $11,507.85(917.91,30,062.27)$ & $26,867.22(7,698.13,58,343.39)$ & 0.091 \\
\hline Calcitriol use, $n(\%)$ & $16(57.1)$ & $21(75.0)$ & 0.158 \\
\hline Ca-based phosphate binders use, $n(\%)$ & $14(50.0)$ & $24(85.7)$ & 0.004 \\
\hline Ca-free phosphate binders use (\%) & $2(7.1)$ & 0 & 0.150 \\
\hline Calcimimetic use, $n(\%)$ & 0 & 0 & - \\
\hline
\end{tabular}

BALP, bone-specific alkaline phosphatase; LVMI, left ventricular mass index; iPTH, intact parathyroid hormone; hsCRP, hypersensitive $\mathrm{C}$ reactive protein; CAC score, coronary artery calcification score; FGF23, fibroblast growth factor 23; BMI, body mass index; Au, Agatston unit.

2 groups was made using either an independent $t$ test or a MannWhitney $U$ test for continuous variables. $\chi^{2}$ test was used to compare the frequencies between groups. Univariate analysis was made using Pearson's correlation coefficients or Spearman's rank. To further analyze the relevant factors for calcification using the CAC score, we perform a multivariate analysis. A logistic regression model was used to screen the variables for CAC (no calcification: a CAC score of 0 and calcification: a CAC score of 1 or more). Independent risk factors associated with the patient survival were assessed using the KaplanMeier survival analysis and multivariate Cox regression model. Results are expressed as hazard ratios with $95 \%$ confidence intervals (95\%). All analyses were performed using IBM SPSS Statistics for Windows, version 20.0 (IBM Corporation, Armonk, NY, USA). A probability $(p)$ value $<0.05$ was considered statistically significant.

\section{Results}

\section{Clinical and Biochemical Characteristics of the \\ Maintenance Dialysis Patients}

Our study population consisted of 65 maintenance dialysis patients undergoing hemodialysis or peritoneal di- alysis. Demographics and biochemical characteristics of these patients are shown in Table 1 . Of 65 participants included, 26 underwent hemodialysis and 39 received peritoneal dialysis. The causes of ESRD were chronic glomerulonephritis in $47(72.3 \%)$ patients, diabetes in 6 (9.2\%) patients, polycystic kidney disease in $6(9.2 \%)$ patients, and the other disease also in $6(9.2 \%)$ patients. The age, dialysis vintage, serum ferritin, $25(\mathrm{OH})$-vitamin $\mathrm{D}$ in hemodialysis patients were significantly higher than those in peritoneal dialysis patients. In contrast, serum albumin was obviously lower in hemodialysis patients than the patients undergoing the peritoneal dialysis.

Serum sclerostin in hemodialysis patients was significantly higher than that in the peritoneal dialysis patients $(632.35 \pm 369.18$ vs. $228.85 \pm 188.92, p<0.001)$. Similarly, compared with peritoneal dialysis patients, the hemodialysis patients had also significantly higher levels of CAC score $(91.8[2.30,665.15]$ vs. $0[0,47.00]$, $p<0.001)$ and LVMI $(188.00 \pm 42.62$ vs. $158.79 \pm 50.10$, $p=0.026)$. 
Table 3. Demographics and biochemistry according to the presence or absence of CAC score

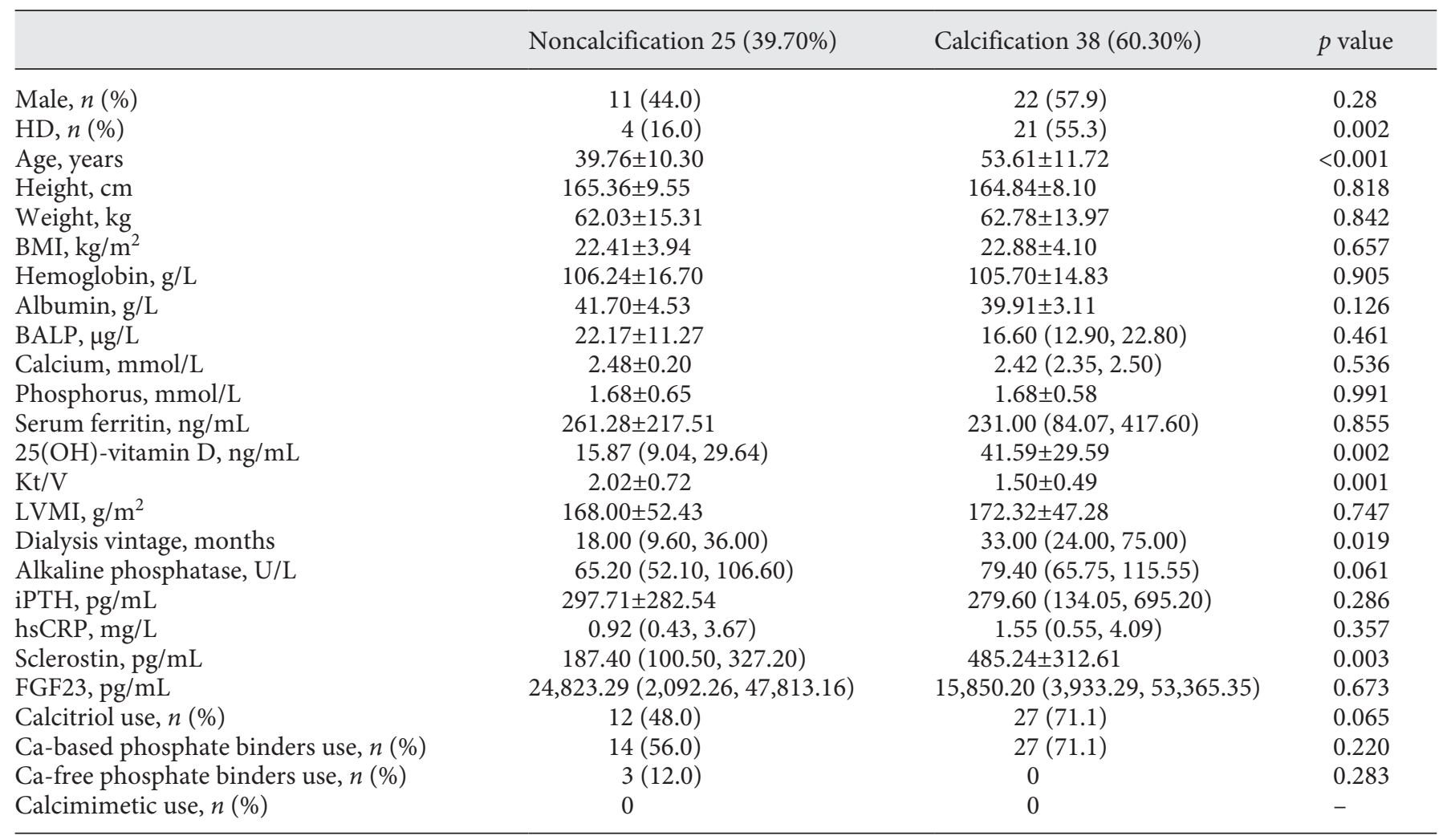

BALP, bone-specific alkaline phosphatase; LVMI, left ventricular mass index; iPTH, intact parathyroid hormone; hsCRP, hypersensitive $\mathrm{C}$ reactive protein; CAC score, coronary artery calcification score; FGF23, fibroblast growth factor 23; BMI, body mass index; Au, Agatston unit.

Table 2 shows the clinical and biochemical parameters in ESRD patients with sclerostin levels above and below the median. Compared with the patients with a serum sclerostin level below the median value of $297.0 \mathrm{pg} / \mathrm{mL}$, those with a level above the median were characterized by male, older age, receiving hemodialysis, lower serum albumin level, lower Kt/V level, lower iPTH level, higher 25-(OH)-vitamin D level, higher CAC level, and higher Ca-based phosphate binders use.

\section{Determinants of CAC in Maintenance Dialysis Patients}

CAC was $60.3 \%$ patients. The prevalence of CAC was higher in hemodialysis patients than that in peritoneal dialysis. CAC was present in $84 \%$ of the hemodialysis patients and $44.7 \%$ of peritoneal patients. Table 3 compares the clinical and biochemical parameters between the patients with and without CAC. The patients with CAC were characterized by older age, longer dialysis duration, and lower $\mathrm{Kt} / \mathrm{V}$. The patients with $\mathrm{CAC}$ also had higher 25-(OH)-vitamin D, higher sclerostin, and had a higher
Table 4. Multivariate logistic regression model of risk factors for CAC score

\begin{tabular}{llll}
\hline Variables & Odds risk & $95 \%$ CI & $p$ value \\
\hline Kt/V & 0.087 & $0.016-0.484$ & 0.005 \\
Age, years & 1.182 & $1.064-1.314$ & 0.002 \\
\hline
\end{tabular}

$R^{2}=0.592, \chi^{2}=31.455, p<0.001$. CAC score, coronary artery calcium score; $\mathrm{CI}$, confidence interval.

proportion of hemodialysis. However, levels of $\mathrm{PTH}$, BALP, and FGF23 were not related to the CAC. In multivariate analysis, older age and high sclerostin level were correlated to the CAC.

In univariate logistic regression analysis, older age, lower Kt/V, and higher serum sclerostin level were associated with the presence of CAC. Multivariate logistic regression analysis revealed that older age and lower $\mathrm{Kt} / \mathrm{V}$ were independent risk factors for CAC (Table 4). The 


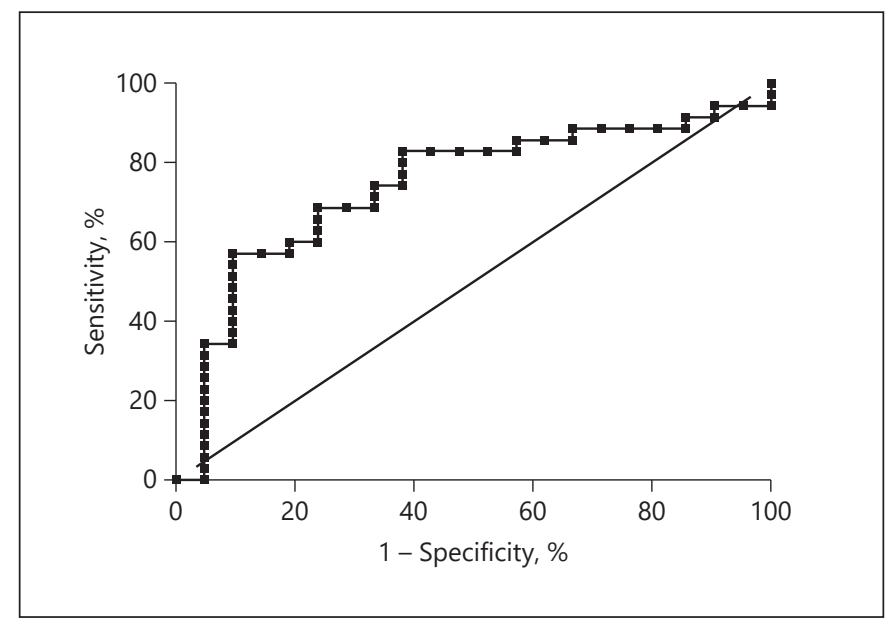

Fig. 2. ROC for prediction of $C A C$ in maintained dialysis patients by sclerostin (AUC $0.74 ; p=0.03$ ). ROC, receiver operating characteristic curve; CAC, coronary artery calcification; AUC, area under the curve.

sclerostin level was not the independent factor related to the CAC $(p=0.066)$.

Receiver operating characteristic curves for prediction of CAC by sclerostin (area under the curve $0.74,95 \%$ confidence interval $0.605-0.878, p=0.03$ ) are shown in Figure 2. The cutoff value of sclerostin was $217.55 \mathrm{pg} / \mathrm{mL}$. The sensitivity was 0.829 , and specificity was 0.619 .

\section{Risk Factors Influencing Survival of Maintenance \\ Dialysis Patients}

Over a follow-up period of 5 years, 51 (78.5\%) of 65 patients were survived. The clinical and biochemical data of the patients in the survival or nonsurvival group are shown in Table 5. Kaplan-Meier survival analysis suggested that age $<60$ years ( $p<0.001$, log-rank test), CAC score $<50 \mathrm{AU}(p=0.010$, log-rank test $)$, and serum sclerostin $<400 \mathrm{pg} / \mathrm{mL}$ ( $p=0.017$, log-rank test $)$ were associated with better survival (shown in Fig. 3). Cox regression analyses revealed that age ( $\geq 60$ years, $p<0.001$ ) and CAC score ( $\geq 50 \mathrm{AU}, p=0.031$ ) were significant risk factors for patient survival (Table 6).

\section{Discussion}

Our study showed that high sclerostin level was related to CAC in maintenance dialysis patients. However, the sclerostin level was not the independent factor correlated to the CAC or patient survival. In the last decade, the Wnt signaling inhibitor, sclerostin, emerged as a key regulator of the bone metabolism. Recently, sclerostin was also demonstrated to be expressed in calcifying vasculature [22]. Since there are some similarities between the mechanism of the bone metabolism and vascular calcification, more and more studies have focused on the relationship between bone metabolic markers and the vascular calcification [23]. As an important bone metabolic marker, sclerostin has been shown to be associated with the bone mineral density and bone turnover, though the nature of this association is not yet fully understood [7, 24, 25]. In addition, sclerostin antibody treatment could induce rapid and sustained increase in bone formation, bone mass, and bone strength in nonoperated bones in rats [26]. However, the clinical application of sclerostin antibodies as an effective treatment of osteoporosis is still in phase III trial [27]. Several clinical and biological variables have been described to be associated with the sclerostin concentration, such as age, CKD, PTH levels, and other bone biomarkers $[28,29]$.

Vascular calcification is common in CKD patients. Even in the early course of CKD when the serum phosphate level was in a normal range, vascular calcification occurred [9]. With CKD progression, the prevalence of vascular calcification is higher in ESRD patients. Furthermore, some studies reported some biological factors influence the relationship between vascular calcification and CKD-MBD [30, 31].

In the present study, we examined a number of new biological factors including BALP, FGF23, and sclerostin to determine which biomarker was associated with vascular calcification in ESRD patients. In line with some previous studies, we found that there was a positive association between the sclerostin levels and CAC $[32,33]$. We could not demonstrate a correlation between higher levels of phosphorus, FGF23, BALP or iPTH, and CAC. Hernandes et al. [34] also found that in dialysis patients with severe hyperparathyroidism, PTH levels were not significantly correlated with CAC. After studying 89 epigastric artery biopsies from patients with end-stage renal disease, Qureshi et al. [17] also found that only sclerostin instead of FGF23 and BALP predicted vascular calcification among the circulating biomarkers of MBD. In contrast to these results, Claes et al. [21] studied 159 CKD patients with an average eGFR of $34 \mathrm{~mL} / \mathrm{min} / 1.72 \mathrm{~m}^{2}$ and found that the association between sclerostin and aortic calcification switched from positive to negative when "CVD history" was introduced in the multivariate analysis [21]. Whether or not the "CVD history" should be included in the multivariate model is controversial because CVD is the outcome of vascular calcification rather than 
Table 5. Clinical characteristics between survivors and nonsurvivors

\begin{tabular}{|c|c|c|c|}
\hline & $\begin{array}{l}\text { Nonsurvivors } \\
(n=14)\end{array}$ & $\begin{array}{l}\text { Survivors } \\
(n=51)\end{array}$ & $p$ value \\
\hline Male (\%) & $9(64.3)$ & $25(49.0)$ & 0.375 \\
\hline $\mathrm{HD}(\%)$ & $7(50.0)$ & $19(37.3)$ & 0.539 \\
\hline Age, years & $61.43 \pm 7.07$ & $42.00(37.00,51.00)$ & $<0.001$ \\
\hline Height, cm & $163.21 \pm 7.94$ & $165.65 \pm 8.73$ & 0.351 \\
\hline Weight, kg & $62.86 \pm 11.76$ & $62.99 \pm 15.40$ & 0.978 \\
\hline Dialysis vintage, months & $24.00(10.50,63.00)$ & $24.00(12.00,60.00)$ & 0.619 \\
\hline Hemoglobin, $\mathrm{g} / \mathrm{L}$ & $111.50 \pm 19.77$ & $104.63 \pm 15.77$ & 0.177 \\
\hline Albumin, $g / L$ & $39.33 \pm 2.95$ & $41.25 \pm 4.23$ & 0.116 \\
\hline $\mathrm{BALP}, \mu \mathrm{g} / \mathrm{L}$ & $15.15(12.98,29.27)$ & $19.50(13.20,22.95)$ & 0.865 \\
\hline Calcium, mmol/L & $2.40 \pm 0.12$ & $2.47 \pm 0.22$ & 0.241 \\
\hline Phosphorus, mmol/L & $1.66 \pm 0.70$ & $1.69 \pm 0.57$ & 0.842 \\
\hline Alkaline phosphatase, U/L & $80.25(68.45,118.48)$ & $74.50(56.70,102.50)$ & 0.207 \\
\hline $\mathrm{iPTH}, \mathrm{pg} / \mathrm{mL}$ & $163.85(37.75,549.18)$ & $272.80(107.60,459.80)$ & 0.430 \\
\hline hsCRP, mg/L & $2.19(0.58,9.17)$ & $1.24(0.48,3.75)$ & 0.219 \\
\hline Sclerostin, pg/mL & $564.04 \pm 354.64$ & $257.25(136.63,478.10)$ & 0.042 \\
\hline CAC score, Agatston unit & $84.50(11.40,748.75)$ & $1.30(0.00,91.80)$ & 0.008 \\
\hline $\mathrm{FGF} 23, \mathrm{pg} / \mathrm{mL}$ & $3,637.13(391.09,64,826.56)$ & $15,844.21(4,982.98,49,109.03)$ & 0.297 \\
\hline Calcitriol use (\%) & $10(71.4)$ & $29(56.9)$ & 0.324 \\
\hline Ca-based phosphate binders use (\%) & $10(71.4)$ & $31(60.8)$ & 0.465 \\
\hline Ca-free phosphate binders use (\%) & 0 & $3(5.9)$ & 0.310 \\
\hline Calcimimetic use (\%) & 0 & 0 & - \\
\hline
\end{tabular}

BALP, bone-specific alkaline phosphatase; LVMI, left ventricular mass index; iPTH, intact parathyroid hormone; hsCRP, hypersensitive $\mathrm{C}$ reactive protein; CAC score, coronary artery calcification score; FGF23, fibroblast growth factor 23 BMI, body mass index; Au, Agatston unit.

its cause. From a clinical point of view, the description of sclerostin as the cross talk between bone and vasculature is still an illusion. The expression of local sclerostin in blood vessels or bones was not related to circulating sclerostin levels, which may partly explain the inconsistency of the previous literatures. Qureshi et al. [17] found that vascular sclerostin mRNA and protein expressions did not differ between calcified and noncalcified vessels, suggesting that the vasculature is not a major contributor to circulating levels. Another study confirmed that the content of sclerostin in bone biopsies was increased despite a concomitant decrease of sclerostin in the serum after a successful kidney transplant [35]. These findings illustrate the limitations of the circulating sclerostin and the critical role of the bone biopsy to understand osteocyte biology in CKD-MBD [36]. Additional clinical and experimental studies are needed to clarify the mechanism of sclerostin in the vascular calcification.
In terms of patient survival, this study revealed that patients in the survival group were younger and had lower sclerostin levels and CAC scores. But after adjusting to correlation factors, older age and higher CAC scores were independent risk factors for high mortality. However, reports on the relationship between sclerostin and patient mortality were highly controversial. After 18 months of follow-up of 673 dialysis patients (HD and PD), the results of the Dutch Cooperative Dialysis Adequacy Study showed that the higher the sclerostin level, the lower the risk of cardiovascular death and all-cause mortality [15]. Contrary to this study, Gonçalves et al. [14] found that the high base level of serum sclerostin was associated with the worse survival in 91 hemodialysis patients. Kanbay et al. [37] examined 173 nondialyzed CKD patients and 47 control patients to show that higher sclerostin level was associated with fatal and nonfatal cardiovacular events. However, the relationship between the serum sclerostin level and all-cause mortality 


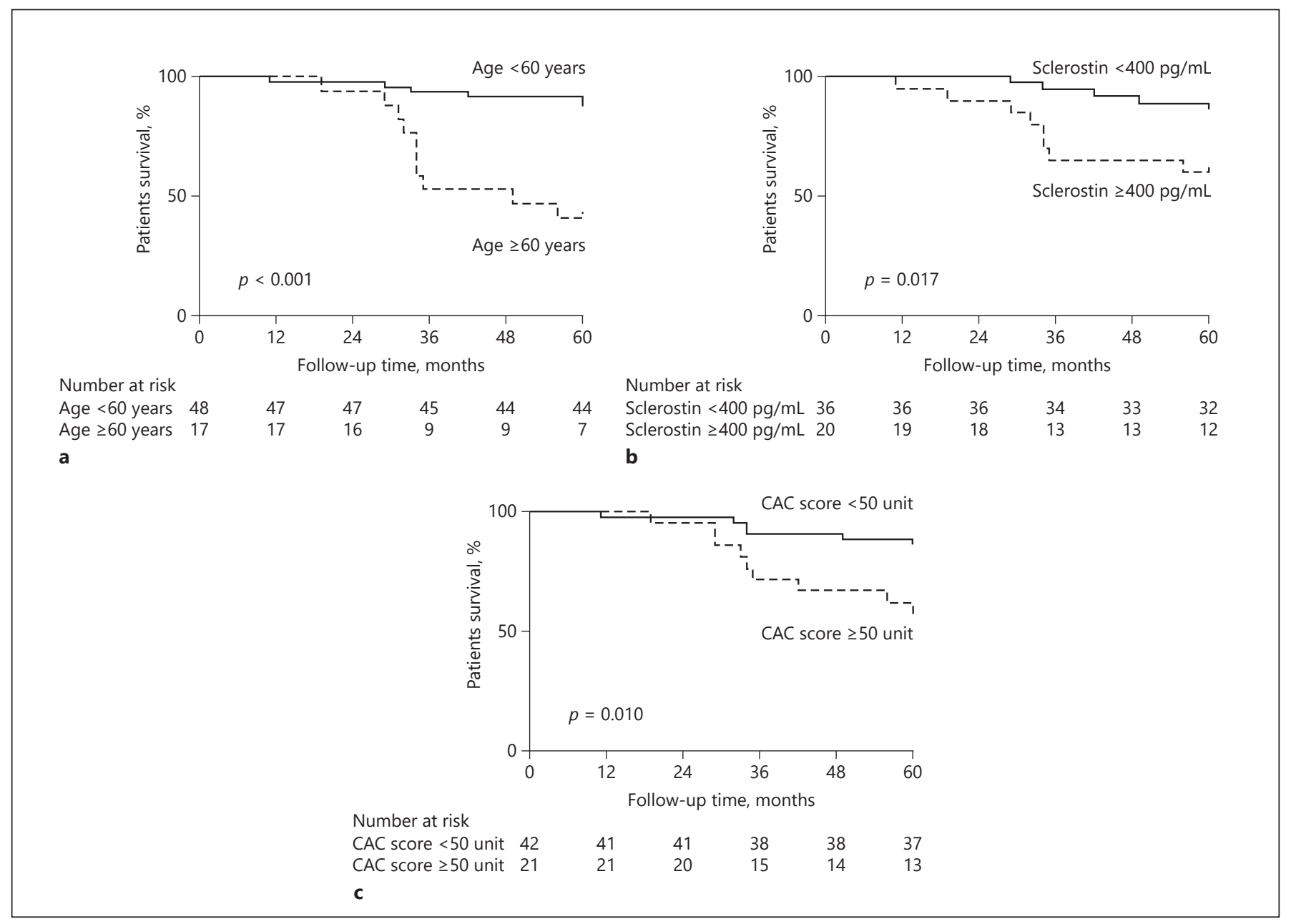

Fig. 3. Kaplan-Meier patient survival curve for maintained dialysis patients with different risk factors. a Age. b Sclerostin level. c CAC score. CAC, coronary artery calcification.

Table 6. Cox proportional HR of patient survival (multivariate analysis)

\begin{tabular}{lllc}
\hline Variable & HR & $95 \%$ CI & $p$ value \\
\hline Age $(\geq 60$ years $)$ & 10.641 & $2.859-39.604$ & $<0.001$ \\
CAC score $(\geq 50$ AU $)$ & 0.288 & $0.093-0.890$ & 0.031 \\
\hline
\end{tabular}

$\mathrm{HR}$, hazard ratio; $\mathrm{CI}$, confidence interval; CAC, coronary artery calcification; AU, Agatston unit.

disappeared after multivariable Cox regression adjustment. Consistent with the previous study, a meta-analysis also demonstrated that circulating sclerostin level was an independent risk factor of all-cause and cardiovascular mortality [38]. In this study, we also found that sclerostin increased significantly in non-survival patients, but its significance disappeared after Cox regression analysis. The reason may be the small number of patients enrolled or the relatively short follow-up duration.

We acknowledge some limitations of our study. First, this is a single-center study, with a small sample size, which may confer the risk of a type 1 statistical error. Second, some baseline characteristics of PD patients at the time of enrollment were different from those of HD patients. Combining PD and HD patients to describe demographic and biochemical data might lead to results bias. Third, as a survival analysis, the 5-year follow-up period was relatively short, and more risk factors may not be found. Fourth, we lack the pathological data on the bone and vessel, which are crucial to delineate the role of sclerostin in the cross talk between bone and vasculature.

We conclude that hemodialysis patients with CAC had significantly higher levels of sclerostin. But sclerostin is 
not a risk factor for CAC. In terms of patient outcomes, lower levels of sclerostin were in the survival patients. But sclerostin levels are not independent risk factors for high mortality in dialysis patients. Whether sclerostin is simply a marker or a central mediator of CAC and mortality in dialysis patients needs to be elucidated by additional studies.

\section{Statement of Ethics}

The study protocol was approved by the Ethics Committee of the First Affiliated Hospital of Nanjing Medical University (Nanjing, Jiangsu, China) and all the patients signed a consent form prior to the study participation.

\section{Conflict of Interest Statement}

The authors have no conflicts of interest to declare.

\section{Funding Sources}

This work was funded by the Priority Academic Program Development of Jiangsu Higher Education Institutions (BL2014080).

\section{Author Contributions}

Research idea and study design: Yifei Ge and Changying Xing; data acquisition: Xueqiang Xu and Xiangbao Yu; data analysis/interpretation: Ningning Wang and Ming Zeng; statistical analysis: Buyun Wu; supervision or mentorship: Bo Zhang and Huijuan Mao.

\section{References}

1 Moe S, Drueke T, Cunningham J, Goodman W, Martin K, Olgaard K, et al. Definition, evaluation, and classification of renal osteodystrophy: a position statement from kidney disease: improving global outcomes (KDIGO). Kidney Int. 2006 Jun;69(11):1945-53.

2 Tentori F, Blayney MJ, Albert JM, Gillespie BW, Kerr PG, Bommer J, et al. Mortality risk for dialysis patients with different levels of serum calcium, phosphorus, and PTH: the dialysis outcomes and practice patterns study (DOPPS). Am J Kidney Dis. 2008 Sep;52(3): 519-30.

3 Kimata N, Albert JM, Akiba T, Yamazaki S, Kawaguchi T, Fukuhara S, et al. Association of mineral metabolism factors with all-cause and cardiovascular mortality in hemodialysis patients: the Japan dialysis outcomes and practice patterns study. Hemodial Int. 2007 Jul;11(3):340-8.

$4 \mathrm{Ng}$ KW, Martin TJ. New functions for old hormones: bone as an endocrine organ. Mol Cell Endocrinol. 2009 Oct 30;310(12):1-2.

5 Vervloet MG, Massy ZA, Brandenburg VM, Mazzaferro S, Cozzolino M, Urena-Torres P, et al. Bone: a new endocrine organ at the heart of chronic kidney disease and mineral and bone disorders. Lancet Diabetes Endocrinol. 2014 May;2(5):427-36.

6 Galitzer H, Ben-Dov IZ, Silver J, Naveh-Many T. Parathyroid cell resistance to fibroblast growth factor 23 in secondary hyperparathyroidism of chronic kidney disease. Kidney Int. $2010 \mathrm{Feb} ; 77(3): 211-8$.

7 Cejka D, Jager-Lansky A, Kieweg H, Weber M, Bieglmayer C, Haider DG, et al. Sclerostin serum levels correlate positively with bone mineral density and microarchitecture in haemodialysis patients. Nephrol Dial Transplant. 2012 Jan;27(1):226-30.

8 London GM, Guerin AP, Marchais SJ, Metivier F, Pannier B, Adda H. Arterial media cal- cification in end-stage renal disease: impact on all-cause and cardiovascular mortality. Nephrol Dial Transplant. 2003 Sep;18(9): 1731-40.

9 Adeney KL, Siscovick DS, Ix JH, Seliger SL, Shlipak MG, Jenny NS, et al. Association of serum phosphate with vascular and valvular calcification in moderate CKD. J Am Soc Nephrol. 2009 Feb;20(2):381-7.

10 Evenepoel P, D'Haese P, Brandenburg V. Sclerostin and DKK1: new players in renal bone and vascular disease. Kidney Int. 2015 Aug;88(2):235-40.

11 Yang CY, Chang ZF, Chau YP, Chen A, Yang WC, Yang $A H$, et al. Circulating $W n t / \beta$ catenin signalling inhibitors and uraemic vascular calcifications. Nephrol Dial Transplant. 2015 Aug;30(8):1356-63.

12 Baron R, Rawadi G. Targeting the Wnt/betacatenin pathway to regulate bone formation in the adult skeleton. Endocrinology. 2007 Jun;148(6):2635-43.

13 Wei W, Zeve D, Suh JM, Wang X, Du Y, Zerwekh JE, et al. Biphasic and dosage-dependent regulation of osteoclastogenesis by $\beta$-catenin. Mol Cell Biol. 2011 Dec;31(23): 4706-19.

14 Goncalves FL, Elias RM, dos Reis LM, Graciolli FG, Zampieri FG, Oliveira RB, et al. Serum sclerostin is an independent predictor of mortality in hemodialysis patients. BMC Nephrol. 2014 Dec 2;15:190.

15 Drechsler C, Evenepoel P, Vervloet MG, Wanner C, Ketteler M, Marx N, et al. High levels of circulating sclerostin are associated with better cardiovascular survival in incident dialysis patients: results from the NECOSAD study. Nephrol Dial Transplant. 2015 Feb; 30(2):288-93.

16 Morena M, Jaussent I, Dupuy AM, Bargnoux AS, Kuster N, Chenine L, et al. Osteoprotegerin and sclerostin in chronic kidney disease prior to dialysis: potential partners in vascular calcifications. Nephrol Dial Transplant. 2015 Aug;30(8):1345-56.

17 Qureshi AR, Olauson H, Witasp A, Haarhaus $\mathrm{M}$, Brandenburg V, Wernerson A, et al. Increased circulating sclerostin levels in endstage renal disease predict biopsy-verified vascular medial calcification and coronary artery calcification. Kidney Int. 2015 Dec;88(6): 1356-64.

18 Lee YT, Ng HY, Chiu TT, Li LC, Pei SN, Kuo $\mathrm{WH}$, et al. Association of bone-derived biomarkers with vascular calcification in chronic hemodialysis patients. Clin Chim Acta. 2016 Jan 15;452:38-43.

19 Lv W, Guan L, Zhang Y, Yu S, Cao B, Ji Y. Sclerostin as a new key factor in vascular calcification in chronic kidney disease stages 3 and 4. Int Urol Nephrol. 2016 Dec;48(12): 2043-50.

20 Jean G, Chazot C, Bresson E, Zaoui E, Cavalier E. High serum sclerostin levels are associated with a better outcome in haemodialysis patients. Nephron. 2016;132(3):181-90.

21 Claes KJ, Viaene L, Heye S, Meijers B, d'Haese P, Evenepoel P. Sclerostin: another vascular calcification inhibitor? J Clin Endocrinol Metab. 2013 Aug;98(8):3221-8.

22 Zhu D, Mackenzie NC, Millan JL, Farquharson C, MacRae VE. The appearance and modulation of osteocyte marker expression during calcification of vascular smooth muscle cells. PloS One. 2011;6(5):e19595.

23 Neven E, Persy V, Dauwe S, De Schutter T, De Broe ME, D'Haese PC. Chondrocyte rather than osteoblast conversion of vascular cells underlies medial calcification in uremic rats. Arterioscler Thromb Vasc Biol. 2010 Sep; 30(9):1741-50.

24 Modder UI, Hoey KA, Amin S, McCready LK, Achenbach SJ, Riggs BL, et al. Relation of age, gender, and bone mass to circulating sclerostin levels in women and men. J Bone Miner Res. 2011 Feb;26(2):373-9. 
25 Delanaye P, Cavalier E, Bouquegneau A, Khwaja A. Sclerostin levels in CKD patients: an important, but not definitive, step on the way to clinical use. Kidney Int. 2015 Dec;88(6): 1221-3.

26 Suen PK, Zhu TY, Chow DH, Huang L, Zheng LZ, Qin L. Sclerostin antibody treatment increases bone formation, bone mass, and bone strength of intact bones in adult male rats. Sci Rep. 2015 Oct 23;5:15632.

27 MacNabb C, Patton D, Hayes JS. Sclerostin antibody therapy for the treatment of osteoporosis: clinical prospects and challenges. J Osteoporos. 2016;2016:6217286.

28 Robling AG, Niziolek PJ, Baldridge LA, Condon KW, Allen MR, Alam I, et al. Mechanical stimulation of bone in vivo reduces osteocyte expression of sost/sclerostin. J Biol Chem. 2008 Feb 29;283(9):5866-75.

29 Delanaye P, Krzesinski JM, Warling X, Moonen M, Smelten N, Medart L, et al. Clinical and biological determinants of sclerostin plasma concentration in hemodialysis patients. Nephron Clin Pract. 2014;128(1-2): $127-34$.
30 Cannata-Andia JB, Roman-Garcia P, Hruska $\mathrm{K}$. The connections between vascular calcification and bone health. Nephrol Dial Transplant. 2011 Nov;26(11):3429-36.

31 Scialla JJ, Kao WH, Crainiceanu C, Sozio SM, Oberai PC, Shafi T, et al. Biomarkers of vascular calcification and mortality in patients with ESRD. Clin J Am Soc Nephrol. 2014 Apr; 9(4):745-55.

32 Brandenburg VM, Kramann R, Koos R, Kruger T, Schurgers L, Muhlenbruch G, et al. Relationship between sclerostin and cardiovascular calcification in hemodialysis patients: a cross-sectional study. BMC Nephrol. 2013 Oct 10;14:219.

33 Kuipers AL, Miljkovic I, Carr JJ, Terry JG, Nestlerode CS, Ge Y, et al. Association of circulating sclerostin with vascular calcification in Afro-Caribbean men. Atherosclerosis. 2015 Mar;239(1):218-23.

34 Hernandes FR, Barreto FC, Rocha LA, Draibe SA, Canziani ME, Carvalho AB. Evaluation of the role of severe hyperparathyroidism on coronary artery calcification in dialysis patients. Clin Nephrol. 2007 Feb;67(2):89-95.
35 Araujo M, Bacelar Marques ID, Graciolli FG, Fukuhara L, Machado Dos Reis L, Custodio $\mathrm{M}$, et al. Comparison of serum levels with bone content and gene expression indicate a contradictory effect of kidney transplantation on sclerostin. Kidney Int. 2019 Nov;96(5): $1100-4$

36 Laster M, Pereira RC, Salusky IB. Unraveling the osteocyte in CKD-MBD post-renal transplantation. Kidney Int. 2019 Nov;96(5):105961.

37 Kanbay M, Siriopol D, Saglam M, Kurt YG, Gok M, Cetinkaya H, et al. Serum sclerostin and adverse outcomes in nondialyzed chronic kidney disease patients. J Clin Endocrinol Metab. 2014 Oct;99(10):E1854-61.

38 Kanbay M, Solak Y, Siriopol D, Aslan G, Afsar B, Yazici D, et al. Sclerostin, cardiovascular disease and mortality: a systematic review and meta-analysis. Int Urol Nephrol. 2016 Dec; 48(12):2029-42. 